\title{
Inhibitory effects of low intensity pulsed ultrasound on osteoclastogenesis induced in vitro by breast cancer cells
}

\author{
Valeria Carina ${ }^{1 *}$, Viviana Costa', Stefania Pagani ${ }^{2}$, Angela De Luca'', Lavinia Raimondi', Daniele Bellavia',
} Stefania Setti ${ }^{3}$, Milena Fini ${ }^{2}$ and Gianluca Giavaresi ${ }^{2}$

\begin{abstract}
Background: Bone tissue is one of the main sites for breast metastasis; patients diagnosed with advanced breast cancer mostly develop bone metastasis characterized by severe osteolytic lesions, which heavily influence their life quality. Low Intensity Pulsed Ultrasound (LIPUS) is a form of mechanical energy able to modulate various molecular pathways both in cancer and in health cells.

The purpose of the present study was to evaluate for the first time, the ability of LIPUS to modulate osteolytic capability of breast cancer cells.

Methods: Two different approaches were employed: a) Indirect method-conditioned medium obtained by MDAMB-231 cell line treated or untreated with LIPUS was used to induce osteoclast differentiation of murine macrophage Raw264.7 cell line; and b) Direct method -MDA-MB-231 were co-cultured with Raw264.7 cells and treated or untreated with LIPUS.

Results: LIPUS treatment impaired MDA-MB-231 cell dependentosteoclast differentiation and produced a reduction of osteoclast markers such as Cathepsin K, Matrix Metalloproteinase 9 and Tartrate Resistant Acid Phosphatase, suggesting its role as an effective and safe adjuvant in bone metastasis management.

Conclusion: LIPUS treatment could be a good and safety therapeutic adjuvant in osteolyitic bone metastasis not only for the induction properties of bone regeneration, but also for the reduction of osteolysis.
\end{abstract}

Keywords: Osteolytic metastasis, Low intensity pulsed ultrasound, Osteoclasts, Breast cancer

\section{Background}

Breast cancer is one of the most common tumors affecting women $[1,2]$. Although the prognosis of breast cancer patients is generally favorable due to early diagnosis and advances in therapies, $20-30 \%$ of patients will develop distant metastases that drastically reduce their survival time $[3,4]$. The most common sites for breast cancer metastasis are bone, liver, lung, brain and skin, and these are associated with the patients' survival outcome $[5,6]$. Bone tissue is indeed a preferential site of metastatic breast cancer cells, which act enhancing mostly bone resorption and inhibiting bone formation. This unbalance in bone remodeling leads to skeletal

\footnotetext{
* Correspondence: valeria.carina@ior.it

${ }^{1}$ IRCCS Rizzoli Orthopedic Institute, Bologna, Italy

Full list of author information is available at the end of the article
}

complications related to the affected bone segment [7] including, severe pain, bone instability, fractures, spinal cord compression, hypercalcaemia and bone marrow aplasia [8], which rapidly deteriorate patients quality of life.

Metastatic breast cancer cells act releasing bone resorption factors that stimulate osteoclastic differentiation directly $[9,10]$ or indirectly acting through osteoblasts [11]. In particular, metastatic breast cancer cells promote osteoclasts formation and activity by secreting osteolytic interleukins (ILs) such as IL-8 and IL-11, as well as TNFoand matrix metalloproteinases (MMP1, MMP2), which are involved in bone matrix destruction [12]. Moreover, metastatic breast cancer cells express factors, such as parathyroid hormone-related peptide (PTHrP) that induces osteoblasts to produce mediators (RANKL, PGE, IL-11), which subsequently

(C) The Author(s). 2018 Open Access This article is distributed under the terms of the Creative Commons Attribution 4.0 International License (http://creativecommons.org/licenses/by/4.0/), which permits unrestricted use, distribution, and 
stimulate osteoclast differentiation from monocyte precursors $[11,13]$.

Strategies to treat bone metastases depend on the number of metastases, their location and prognosis. A radiotherapeutic or systemic approach is preferred in case of multiple metastases or lesions sensitive to adjuvant therapies. If metastatic lesions are unresponsive to chemotherapy, but their localization allows surgery and the patient presents good clinical conditions, it is preferable to treat metastases surgically $[14,15]$. If surgery is not recommended, or if the prognosis is unfavorable, patients should undergo palliative care with the primary aim of alleviating debilitating pain and improving their quality of life. Bone pain is usually managed via a multimodality approach, including the use of analgesic medications, cytotoxic chemotherapy, hormone-deprivation therapy, radiation therapy as well as administration of bisphosphonates, bone-seeking radiopharmaceuticals [16-18] or minimally invasive percutaneous therapies such as radiofrequency, thermoablation with microwave [19, 20], cryoablation [21], alcholization [22], electrochemotherapy [23] or high intensity focused ultrasounds (HIFU) [24].

Recently, the therapeutic potential of ultrasound in pain reduction and oncology has been evaluated. The possibility of using ultrasounds with different parameters: intensity (Low $<3 \mathrm{~W} / \mathrm{cm}^{2}$; High $\geq 3 \mathrm{~W} / \mathrm{cm}^{2}$ ) and frequency (Low 20-200 kHz; High 1-20 MHz) [25] allows their application in various fields, ranging from tissue ablation (using high intensity focused ultrasoundHIFU) $[26,27]$ to tissue regeneration (using low intensity ultrasound) $[28,29]$.

Nowadays, HIFU, or focused ultrasound (FUS), is used in oncological therapy not only to ablate metastasis, but also to relief pain [24, 30]. Like HIFU, low intensity pulsed ultrasound (LIPUS) is transmitted into tissues as an acoustic pressure wave, leading downstream effects by translating this mechanical signal into a biochemical response via integrin mechano-receptors. Mechanical forces (mechanotransduction), either generated by cell contractions or from external sources, have been demonstrated to have strong effects on cell differentiation, growth, and survival [31]; [32]. Through mechanotransduction mechanisms, LIPUS is able to trigger alterations in gene expression. The most studied pathways modulated by LIPUS concern regeneration of bone tissue and acceleration of bone repair processes by up-regulating bone specific genes and inducing osteoblast differentiation [33,34]. In addition it is known that LIPUS is able to modulate gene expression and release soluble factors involved in inflammatory and membrane degradative processes such as ILs, MMPs and MAPKs in both healthy and cancer cells [33, 35-37].

Starting from these knowledges on osteoblasts and cancer cells, the aim of the present study was to evaluate the effect of LIPUS on the osteoclastic differentiation process induced by breast cancer cells. Within bone metastatic microenvironment induced by breast cancer cells, different cell types coexist such as healthy bone cells, osteoblasts and osteoclasts, which are continually stimulated by both cancer cells and osteolytic processes. By considering the modulating effect of LIPUS on bone cells, we hypothesized, for the first time, that LIPUS could modulate the release of mediators from breast cancer cells, which could be able to act on osteoclast, thus reducing bone resorption and preventing metastatic osteolytic progression. In this sense, this study allowed to achieve the first information for the development of a new therapeutic approach for metastasis treatment, where LIPUS become an adjuvant of the current pharmacological therapy. In this regard we employed murine macrophage cells (Raw264.7) that are a widely used system to analyze osteoclastic differentiation [38, 39] and MDA-MB-231,a metastatic breast cancer cell line that is largely employed to study osteoclastic differentiation in co-culture [40] or conditioned medium systems [38]. Two different culture approaches were applied: (a) indirect method where conditioned medium obtained by the breast cancer cell line MDA-MB-231 treated or untreated by LIPUS was used to induce osteoclast differentiation of murine macrophage Raw264.7 cell line; (b) direct method where MDA-MB-231 cells were co-cultured with Raw264.7 cells and treated or untreated with LIPUS.

\section{Methods \\ Cell lines}

The breast cancer cell line MDA-MB-231 (HTB-26 ${ }^{\mathrm{mm}}$ ), purchased from ATCC ${ }^{\circ}$, was cultured at $37{ }^{\circ} \mathrm{C}$ and $5 \%$ $\mathrm{CO}_{2}$ in Dulbecco's modified Eagle's medium with high glucose (DMEM) (Euroclone S.p.A., Pero, Milano, Italy) supplemented with $10 \%$ heat-inactivated fetal bovine serum (FBS,) (Lonza, Verviers, Belgium), $1 \mathrm{mM}$ Sodium Pyruvate (Euroclone), $2 \mathrm{mM}$ glutamine, $100 \mathrm{U} / \mathrm{ml}$ penicillin and $100 \mu \mathrm{g} / \mathrm{ml}$ streptomycin (Gibco, Invitrogen Corp., Carlsbad, CA, USA). Murine macrophage Raw264.7 cells were purchased from $\mathrm{ATCC}^{\circ}$ and cultured at $37^{\circ} \mathrm{C}$ and $5 \% \mathrm{CO}_{2}$ in DMEM supplemented with $10 \% \mathrm{FBS}, 2 \mathrm{mM}$ glutamine and antibiotics (100 U/ml penicillin, $100 \mu \mathrm{g} / \mathrm{ml}$ streptomycin).

\section{Conditioned media preparation}

MDA-MB-231 cells were seeded in 12-well plates at a density of 20,000 cells/well to prepare different conditioned media for subsequent studies and then divided in two groups. A group of MDA-MB-231 cells was stimulated with LIPUS $20 \mathrm{~min} /$ day for 10 days (Fig. 1a). The medium was changed and discarded at day 3 and 6 , then for the medium of the final 4 days LIPUS conditioned medium (LCM) was collected, filtered $(0.22 \mu \mathrm{m})$, aliquoted and frozen at $-80{ }^{\circ} \mathrm{C}$. The other group of 


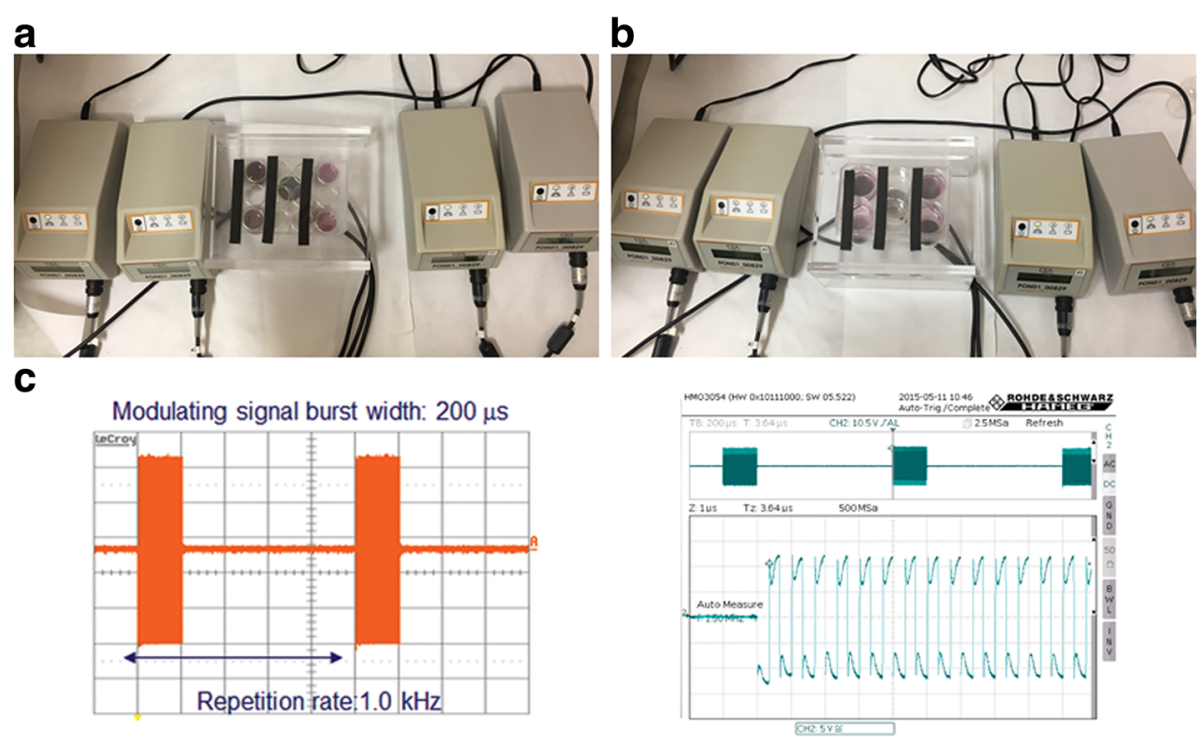

Fig. 1 LIPUS set-up experiment. Upper panel: LIPUS transducer device. Bottom panel: characteristic of the ultrasound signal: $200 \mu$ s burst of $1.5 \mathrm{MHz}$ sine waves repeated at $1 \mathrm{kHz}$ (c). MDA-MB-231 cells were seeded in 12-well plates employing four wells/plate. Two wells were placed on swich-on transducer receiving LIPUS stimuli to obtain LCM the other two were placed on swich-off transducer and used as untreated group to collect CM. LIPUS treatment was performed for 20 min/day for 10 days (a). MDA-MB-231 cells were seeded in 6-well plates using four wells/plate. After $24 \mathrm{~h}$, a transwell insert was inserted into each well and Raw264.7 cells were seeded in the upper compartment. Two wells were placed on swich-on transducer receiving LIPUS stimuli to obtain LIPUS_CC group, the other two were placed on swich-off transducer and used as untreated to obtain Untreated_CC group. LIPUS treatment was performed for $20 \mathrm{~min} /$ day for 10 days (b)

MDA-MB-231 cells was maintained at the same conditions of the previous group but without LIPUS stimulation, then conditioned medium (CM) was harvested and stored as described above.

\section{Raw264.7 osteoclastic differentiation}

Raw264.7 cells were seeded in 24-well plates at a density of 5000 or 2500 cells/well and treated (for 6 days for gene expression analysis and for 10 days for protein release evaluation) with $10 \%$ of conditioned medium derived by untreated (CM) or LIPUS treated (LCM) MDA-MB-231. Alternatively, as positive control, Raw264.7 were seeded at the same density and treated with $25 \mathrm{ng} / \mathrm{ml}$ human recombinant RANK Ligand (Gibco, Life Technologies, USA) for 6 or 10 days for gene expression analysis and for protein release evaluation, respectively. The medium was changed every three days.

\section{Co-cultures}

MDA-MB-231 cells were seeded in 6-well plates at a density of 30,000 cells/well. After $24 \mathrm{~h}$, a transwell insert (pore size $0.4 \mu \mathrm{m}$ ) (Millipore, Cork, Ireland) was inserted into each well and Raw264.7 cells were seeded in the upper compartment at a density of 15,000 cells/well. Then, co-cultures were divided in two groups: a group stimulated with LIPUS $20 \mathrm{~min} /$ day for 10 days (LIPUS_CC); and the other group maintained at the same conditions of the previous group but without LIPUS stimulation (Untreated_CC) (Fig. 1b).

\section{LIPUS treatment}

The LIPUS exposure device was manufactured by IGEA SpA (Carpi-Modena, Italy). It consisted of an array of 5 autonomous transducers, designed for use in a multi-well culture plate. LIPUS signal consisted of $200 \mu$ s burst of $1.5 \mathrm{MHz}$ sine waves, repeating at $1 \mathrm{kHz}$ and delivering $30 \mathrm{~mW} / \mathrm{cm}^{2}$ SATA intensity, transmitted through the bottom of the culture dish via the coupling gel between the ultrasonic transducer and the dish (Fig. 1a-c). A calibrated force balance measured the power of the collimated ultrasound beam emitted from the transducer (Ultrasound Power Meters UPM-DT-1AV, Ohmic Instruments, St. Charles - MI, US). The mediated power was $33.7 \mathrm{~mW} /$ $\mathrm{cm}^{2}[33,41]$.

\section{MDA-MB-231 cell viability}

WST-1 colorimetric reagent (Roche Diagnostics $\mathrm{GmbH}$, Manheim, Germany) was used to evaluate MDA-MB-231cell viability after 10 days of LIPUS treatment. Briefly, WST-1 reagent $(10 \% \mathrm{vol} / \mathrm{vol})$ was added to the cell monolayer in each well. After $4 \mathrm{~h}$ of incubation, formazan dye produced by viable cells was quantified spectrophotometrically at $450 \mathrm{~nm}$ by Bio-Rad Microplate Reader (Bio-Rad Laboratories, Hercules, CA, USA) and 
Table 1. Initrogen ${ }^{\mathrm{TM}}$ sequences employed for gene expression studies

\begin{tabular}{lll}
\hline Gene & Forward primer sequence (5'-3') & Reverse primer sequence (3'-5') \\
\hline Gapdh & CCCAGAAGACTGTGGATGG & CAGATGGGGGTAGGAACAC \\
Acp5 & GCGACCATTGTTAGCCACATACG & CGTTGTGTCGCACAGAGGGAT \\
Ctsk & GCGTTTTCTTATTCCGAGC & CAGCAGAGGTGTGTACTATG \\
Mmp9 & GCTGACTACGATAAGGACGGCA & GCGGCCCTCAAAGATGAACGG \\
\hline
\end{tabular}

results were reported as percentage of viable cells compared to untreated LIPUS MDA-MB-231.

\section{TRAP staining assay}

Raw264.7 cells were cultured as described above (Raw264.7 osteoclastic differentiation and co-culture paragraphs) and stained for detection of tartrate resistant acid phosphatase (TRAP) activity, according to the manufacturer's protocol (Acid Phosphatase, Leukocyte TRAP Kit; Sigma-Aldrich, St. Louis, MO, USA) and evaluated by light microscopy (Eclipse Ti-S, Nikon). Multinucleated TRAP ${ }^{+}$cells containing more than three nuclei were scored as mature osteoclasts. $\mathrm{TRAP}^{+}$cells were counted for each condition from three different fields in three independent experiment.

\section{qRT-PCR analysis}

Total RNA from Raw264.7 cells treated as described above (Raw264.7 osteoclastic differentiation and co-culture paragraphs) was extracted using a PureLink ${ }^{\text {mix }}$ RNA Micro Kit $\left(\right.$ Invitrogen $\left.^{\mathrm{Tm}}\right)$ and reverse-transcribed with a High Capacity cDNA Reverse Transcription Kit (Applied Biosystems ${ }^{\text {Tw }}$, Life Technologies - Italy) following the manufacturer's instructions. Each cDNA sample was tested in duplicate. qRT-PCR analysis was performed by using the SYBR $^{\circ}$ Green Real-Time PCR Master Mix (Applied Biosisystems $\left.^{\mathrm{Tm}}\right)$. Custom made primers (Invitrogen ${ }^{\mathrm{Tx}}$ ) employed are reported in Table 1. The mean threshold cycle was used for the calculation of relative expression using the $2^{-\Delta \Delta \mathrm{Ct}}$ method, against Gapdh as housekeeping gene and Raw264.7 control cultures (CTR - maintained in their growth medium) as calibrator [42].

\section{ELISA assay}

Raw264.7 cells were treated as described above (Raw264.7 osteoclastic differentiation and co-culture paragraphs) and MMP9 (Matrix Metalloproteinase 9) and CTSK (Cathepsin K) secreted by Raw264.7 cells were quantified respectively by mouse MMP9 ELISA assays and CTSK ELISA assay (Wuhan Fine Biological Technology Co., Ltd) according to the manufacturer's instructions and normalized vs. dsDNA content calculated by using fluorimetric Quant-iTPicoGreen dsDNA Assay Kit (Invitrogen ${ }^{\mathrm{Tu}}$, Life Technologies - EuroClone S.p.A, Pero-Milan, Italy).

\section{SEM analysis}

To perform SEM analysis, Raw264.7 cells were seeded on glass coverslips and cultured as described above (Raw264.7 osteoclastic differentiation and co-culture paragraphs). Each coverslip was fixed at room temperature for $1 \mathrm{~h}$ in $2.5 \%$ glutaraldehyde in $0.1 \mathrm{M}$ Phosphate buffer at $\mathrm{pH}$ 7.4. The fixed samples were dehydrated in graded series of ethanol $(10,20,30,50,70,90,100 \%$ for $10 \mathrm{~min}$ each, with 3 changes at $100 \%$ ), and finally twice in hexamethyldisilazane. After gold-sputtering (B7340 Manual Sputter Coater Assing $\mathrm{SpA}$ ) samples were then examined by scanning electron

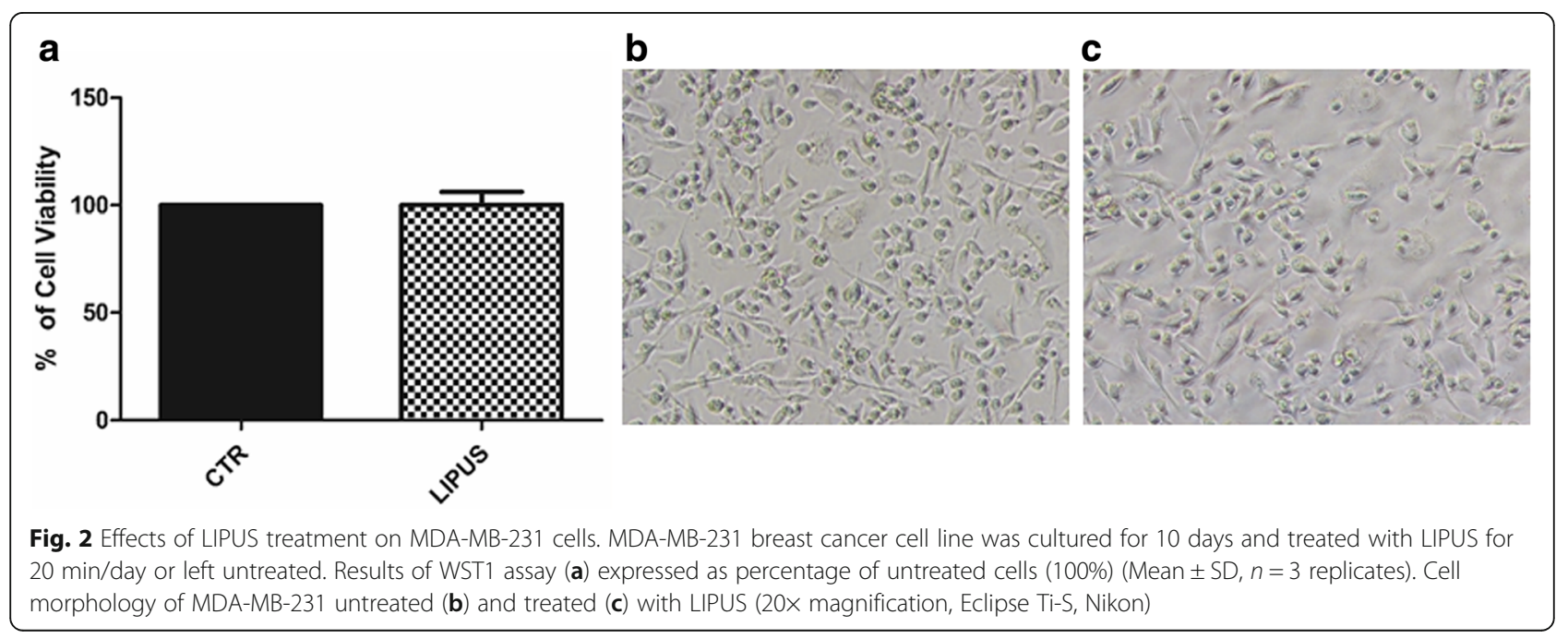


microscopy (EVO LS - ZEISS, Assing SpA). Backscattered electron observations were performed at $20 \mathrm{kV}$.

\section{Statistical analysis}

Statistical analysis was performed using R v.3.3.3 software [43]. Data were reported as bar chart or mean \pm SD at a significant level of $p<0.05$. After having verified normal distribution (Shapiro-Wilk test) and homogeneity of variance (Levene test), data were analyzed by means of Student $t$ test by considering we hypothesized that: (1) the recombinant RANKL was able to induce osteoclastic differentiation in Raw264.7 cell line; (2) the conditioned medium of LIPUS treated MDA-MB-231 cells (LCM) was able to interfere on Raw264.7 cells osteoclastic differentiation compared to the conditioned medium of untreated ones (CM); (3) LIPUS treatment of co-cultured MDA-MB-231 and Raw264.7 cells (LIPUS_CC) was able to reduce osteoclastic differentiation in Raw264.7 cells compared to untreated co-cultures (Untreated_CC). The effect size of comparisons derived by these hypotheses was reported as standardized Cohen's $d$, which is defined as the difference between two means divided by pooled standard deviation. For all the tests performed, 3 independent experiments were conducted in triplicate for each group.

\section{Results}

\section{Cell viability}

To evaluate the effects of LIPUS treatment on cancer cells viability, the LIPUS stimuli on MDA-MB-231 was measured. LIPUS stimulation for 10 days did not influence $(d=0.09, p=0.987)$ viability of MDA-MB-231 cell culture, as shown by WST1 assay (Fig. 2a) and optical microscope analysis showed that it did not affect cell morphology either (Fig. $2 b$ and c), demonstrating that treatment with LIPUS is usable in a tumor system.

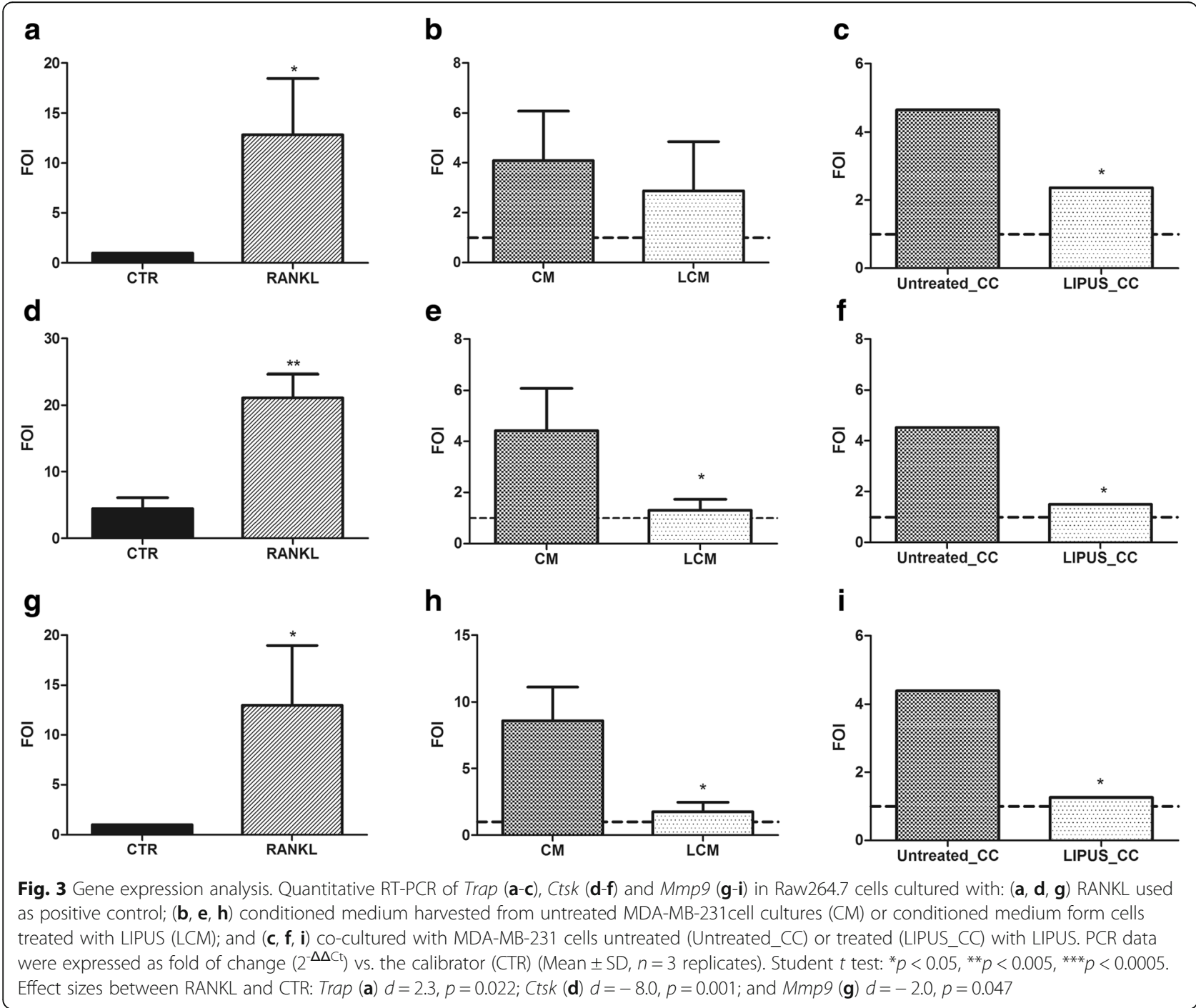




\section{Osteoclast differentiation markers}

We assessed weather LIPUS treatment could influence MDA-MB-231 ability to induce osteoclastic differentiation in Raw264.7 cell line. To evaluate the system reliability, we cultured Raw264.7 cells in presence of RANKL treatment as positive control (Fig. 3a, d and g; Fig. 4a and d; Fig. 5b and c; and Fig. 6b).

Firstly, we evaluated the effects of LIPUS treatment on gene expression in Raw264.7 cells. Quantitative RT-PCR analysis showed an important gene expression modulation of osteoclast differentiation markers after LIPUS stimulation. In particular, in the indirect method cells treated with MDA-MB-231 conditioned medium obtained after LIPUS treatment (LCM) showed a significant decrease of Ctsk $(d=-2.6, p=0.035)$ and Mmp9 $(d=-3.0, p=0.024)$ expression compared to cells treated with CM (Fig. 3e and $\mathrm{h}$ ). In the direct method, LIPUS treatment on co-cultures (LIPUS_CC) caused a significant decrease of Trap $(d=-2.8, p=0.026)$, Ctsk $(d=-2.3, p=0.044)$ and Mmp9 expression $(d=-2.8, p=0.026)$ (Fig. 3c, $\mathrm{f}$ and i) compared to the untreated group (Untreated_CC), showing a general higher effect in co-culture system for Trap and Ctsk gene modulation.

Subsequently, we evaluated the effects of LIPUS treatment on proteins involved in bone resorption both by evaluating the release of CTSK and MMP9 and by assessing TRAP activity.
ELISA assays showed an important modulation of osteoclast differentiation markers release confirming gene expression data. In the indirect method, both CTSK and MMP9 release resulted decreased in the LCM group $(d=-4.2, p=$ 0.007 and $d=-2.4, p=0.042$, respectively) (Fig. $4 \mathrm{~b}$ and e). In the direct method, LIPUS treatment caused a stronger decrease in CTSK and MMP9 release $(d=-4.2, p=0.007$ and $d=-10.8, p<0.0005$, respectively) than in the indirect method (Fig. 4c and f).

TRAP staining showed a significant reduction of multinucleate TRAP ${ }^{+}$cells both in LCM $(d=-13.9, p<0.0005)$ and LIPUS_CC group $(d=-11.0, p<0.0005)$ (Fig. 5f, i) differently from CM and Untreated_CC groups.

These data show that LIPUS treatment is able to reduce the ability of MDA-MB-231 to induce osteoclastic differentiation of Raw264.7 cells in both systems.

\section{SEM analysis}

Ultrastructural analysis demonstrated that a large number of Raw264.7 cells cultured in CM medium or in Untreated_CC (Fig. 6c and e) showed a characteristic osteoclastic morphology: cells appeared large, flat and with a ruffled border with numerous filopodia like in the RANKL treated group (Fig. 6b). On the contrary, the majority of cells cultured in LCM or in LIPUS_CC (Fig. 6d-f) showed amorphology similar between them and among undifferentiated Raw264.7, demonstrating that LIPUS treatment

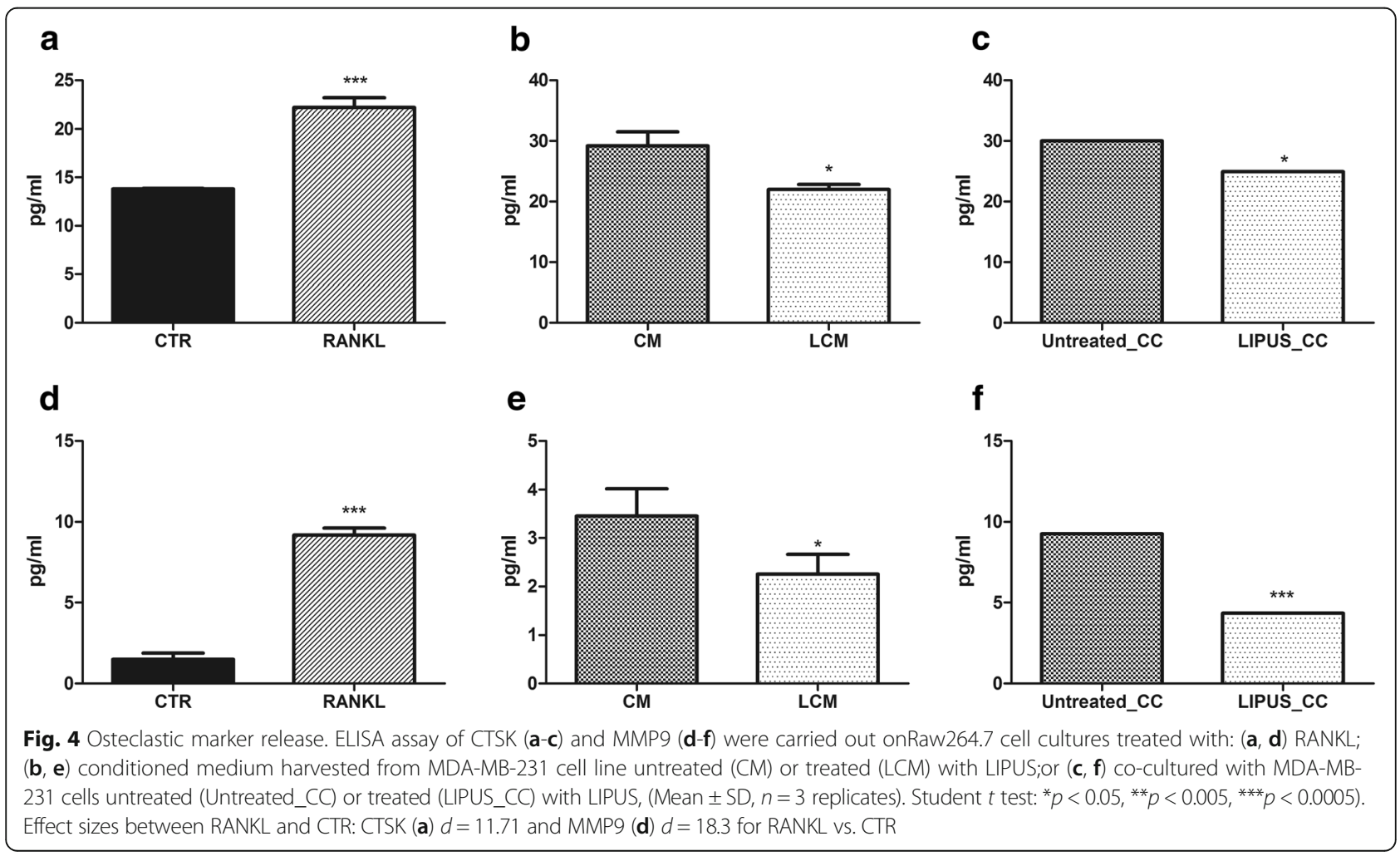




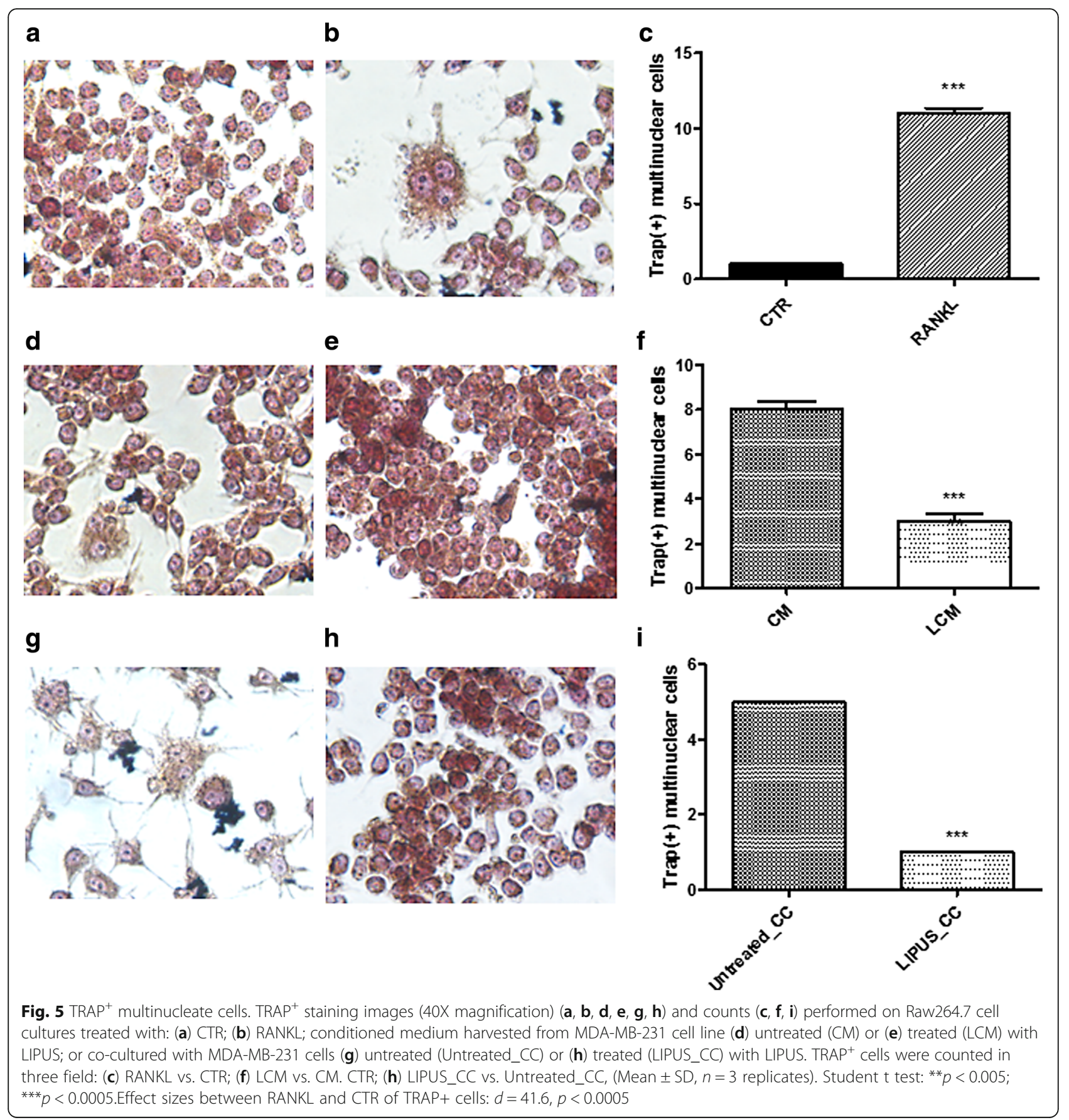

was able to reduce the ability of MDA-MB-231 to induce osteoclastic differentiation of Raw264.7 cells in both systems.

\section{Discussion}

Ultrasound energy is a pressure wave that can produce both mechanical and thermal effects [27], which are not drastically separated [25] and whose applications are strongly dependent on intensity and frequency.
Ultrasound therapy can therefore be broadly divided into "low power" and "high power" applications, able to trigger a range of biological effects in relation to the exposure levels employed; although there is still no widely accepted definition of low-intensity ultrasound [44] the "low power" group includes physiotherapy and fracture repair (generally $30 \mathrm{~mW} / \mathrm{cm}^{2}$, with $200 \mathrm{~ms}$ pulses and 1.5 MHz) [45], sonophoresis, sonoporation and gene therapy (usually $1.0-2.0 \mathrm{MHz}$ at an intensity of 0.5 to $3.0 \mathrm{~W} / \mathrm{cm}^{2}$ ) [44], whereas the most common use of 

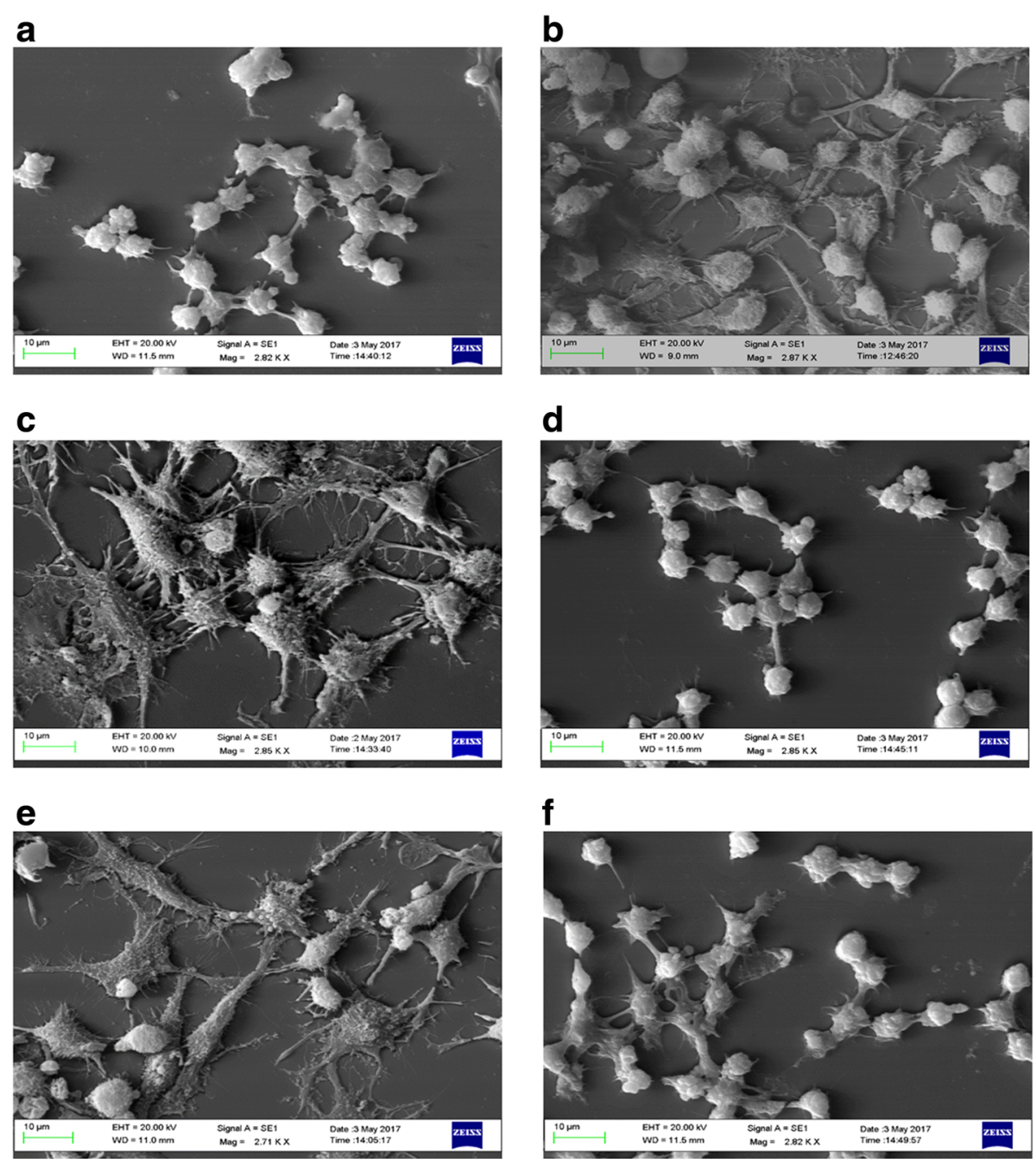

Fig. 6 Ultrastructural analysis of Raw264.7 morphology. Panels are representative SEM imagesofRaw264.7 cell cultures treated with: (a) CTR; (b) RANKL; conditioned medium harvested from MDAMB231 cell line (c) untreated (CM) or (d) treated (LCM) with LIPUS; or co-cultured with MDAMB231 cells (e) untreated (Untreated_CC) or (f) treated (LIPUS_CC) with LIPUS

"high power" ultrasound in medicine is high-intensity focused ultrasound (HIFU) (employed generally at an intensity $\geq 3 \mathrm{~W} / \mathrm{cm}^{2}$ and a frequency of $1-20 \mathrm{MHz}$ ) [27]. While useful therapeutic effects are now being demonstrated clinically, the mechanisms by which they happen are often not well understood [27]. The thermal effects of LIPUS are minimal, because of low intensity and pulsed output mode: the energy transported by an ultrasonic beam is attenuated passing through tissues, since it is scattered out elsewhere in the tissue. The ultrasound energy passing down into the tissues determines tissue molecular vibration, resulting in heat generation and tissue thermal changes [46]. The mechanical effects include acoustic streaming, secondary steady flow generated from the primary oscillatory [47], and stable cavitation, formation and growth of gas bubbles by accumulation of dissolved gas in the medium [46], which contribute mainly to the non-thermal effects in the application of LIPUS. The first mechanical effect can affect membrane permeability, diffusion rate and alteration of protein synthesis, cellular secretion, and sonoporation, while the second one improves drugs transport and cellular up-take [27].

LIPUS is a clinically established, widely used and FDA approved therapy to enhance bone growth during healing of non-union, fractures and other osseous defects $[28,48]$. LIPUS induces mechanical stress in bone that, in turn, stimulates ossification of a soft callus through the modulation of calcium ion channels [49-52].

Conversely HIFU is already employed for tumor ablation $[53,54]$ and pain reduction [55] by causing tissue necrosis through the conversion of mechanical energy into heat (up to $80-90{ }^{\circ} \mathrm{C}$ within tissues) and unstable cavitation, which is the formation and immediate and violent collapse of gas-filled bubbles [26, 56, 57]. 
More recently, the use of LIPUS has been proposed in anticancer therapy due to its ability to increase the effects of anticancer drugs $[58,59]$. LIPUS is able to modulate the expression of various soluble factors such as ILs and MMPs in both healthy and tumor cells [35-37] and breast cancer osteolytic capability depends on the release of these same soluble factors [12, 13]. Previously, Sawai et al. suggested that LIPUS used for bone metastases from renal and prostate cancer was able to induce osteoblastic differentiation without inducing cancer proliferation, vascularization, and migration [37]. The current study for the first time evaluated the effect of LIPUS on osteoclast precursors differentiation induced by osteolytic metastatic breast cancer cells, which were directly exposed to LIPUS to better mimic tumor niche.

We used a system consisting of metastatic breast cancer cells (MDA-MB-231) and murine macrophage cells (Raw264.7) [38, 60]. In particular, we evaluated osteoclastic morphology and activity by the expression and/or the release of typical markers: CTSK, a proteolytic enzyme responsible of bone resorption, MMP9, a gelatinase secreted by mature osteoclast involved in bone resorption and, finally, TRAP, a regulator of bone resorption through bone matrix degradation and highly expressed in terminally differentiated osteoclasts [61-63].

Our viability data showed no significant effects of LIPUS treatment on breast cancer cell lines; in particular, MDA-MB-231 viability was not altered after 10 days of LIPUS treatment similar to Sawai's results about LIPUS effect on osteosarcoma and several others cancer cell lines. LIPUS treatment was able to decrease the capability of breast cancer cell culture medium to induce osteoclastic differentiation in Raw264.7, showing a significant reduction of multinucleate $\mathrm{TRAP}^{+}$cells,as well as CTSK and MMP9 expression and release, using both direct and indirect approaches.

The current results suggested that the effect of LIPUS treatment on adopted in vitro microenvironment model determine the release of molecules, acting on osteoclast precursors limiting their differentiation. Previous studies about the directly effect of LIPUS treatment on osteoclasts alone showed contrastant results: Feres et al. [64] and Miyazaki et al. [65] showed an increase in osteoclast activity following treatment with LIPUS, while Monici et al. and Chen et al. [66, 67], showed a decrease in the expression of cytoskeletal components and markers of osteoclast growth, differentiation, and activity. In the tumor microenvironment, cancer cells coexist with preosteoclasts and release many soluble factors such as IL8, IL11, MMP1, MMP2, $\mathrm{TNF} \alpha$, and $\mathrm{PGE}_{2}$, which determine the direct osteolytic capability of breast cancer cells [12]. Interestingly, LIPUS treatment in co-culture system, which is closer to an in vivo setting, seemed to have a greater inhibitory effect on the osteolytic capacity of metastatic breast cancer cells, in particular for Trap and Ctsk expression and CTSK and MMP9 protein release. However, in our preliminary studies on IL8 and TNF $\alpha$ release by MDA-MB-231 treated and untreated with LIPUS, we did not find any association with osteoclast differentiation reduction (data not shown); therefore, we think that further investigations, such as proteomic profiling on MDA-MB-231 secretoma, might be useful to understand the pathways involved in this mechanism.

\section{Conclusions}

In conclusion, our data suggest that LIPUS treatment is able to reduce in vitro osteolytic behavior of metastatic breast cancer cells. To overcome the current limit of this in vitro study, further investigations will be performed in $3 \mathrm{D}$ culture system in order to understand the reciprocal cellular cross-talk within the tumor microenvironment and the relative molecular basis involved [68]. Once the best treatment protocolsin the 3D system are identified, it will be possible to study LIPUS effects in vivo using a rat metastatic breast cancer model [69].

\begin{abstract}
Abbreviations
CM: Conditioned Medium; CTR: Control; CTSK: Cathepsin K; ELISA: EnzymeLinked Immunosorbent Assay; FDA: Food and Drug Administration; FUS: Focused Ultrasound; GAPDH: Glyceraldehyde-3-Phosphate Dehydrogenase; HIFU: High Intensity Focused Ultrasound; LL: Interleukin; LCM: LIPUS Conditioned Medium; LIPUS: Low Intensity Pulsed Ultrasound; LIPUS_CC: LIPUS treated Co-cultures; MAPKs: Mitogen-Activated Protein Kinases; MMP: Matrix Metalloproteinase; PGE: Prostaglandine;

PTHrP: Parathyroid hormone-related peptide; qRT-PCR: quantitative Real Time- Polymerase Chain Reaction; RANKL: Receptor activator of nuclear factor kappa-B ligand; SATA: Spatial Average, Temporal Average; SD: Standard Deviation; SEM: Scanning Electron Microscopy; TNF: Tumor Necrosis Factor; TRAP: Tartrate Resistant Acid Phosphatase; Untreated_CC: Untreated Cocultures; WST-1: [2-(4-lodophenyl)-3-(4-nitrophenyl)- 5-(2,4-disulfophenyl)-2Htetrazolium]
\end{abstract}

\section{Acknowledgements}

The Authors wish to thank the National Operational Programme for Research and Competitiveness 2007-2013 for the equipment facilities obtained - Project PON03_00011 "Potenziamento strutturale di una rete di eccellenza per la ricerca preclinica e clinica sullaterapia personalizzata in oncologia e in medicina rigenerativa". The study was developed with the contribution of the Italian Ministry of Health by the 'Ricerca Corrente' funding.

\section{Funding}

This work was performed thanks to the aid of National Operational Programme for Research and Competitiveness 2007-2013 for the equipment facilities obtained - Project PON03_00011 "Potenziamento strutturale di una rete di eccellenza per la ricerca preclinica e clinica sulla terapia personalizzata in oncologia e in medicina rigenerativa". The study was developed with the contribution of the Italian Ministry of Health by the 'Ricerca Corrente' funding.

\section{Availability of data and materials}

Dataset are available on (https://figshare.com/s/77d335ed023cc33368b9).

\section{Authors' contributions}

$\mathrm{CV}$ : conception and design, analysis and interpretation of data and revising article critically; CV: drafting the article and interpretation of data, DLA design and interpretation of data; DB: drafting of the article, RL: conception and interpretaion of data; PS: revising article critically; SS: revising article critically; FM: revising critically, GG: conseption and design, analysis of data and revising article critically. DB, VCarina, VCosta, ADL and LR contributed to the manuscript by working at the Technology Platform of Tissue Engineering, 
Theranostics and Oncology (GG), a laboratory started-up by the Rizzoli Orthopedic Institute in Palermo (Italy) with the grants also of National Operative Program projects (PON, MIUR). All authors read and approved the final manuscript.

\section{Ethics approval and consent to participate}

Not applicable

\section{Consent for publication}

Not applicable

\section{Competing interests}

The authors declare that they have no competing interests.

\section{Publisher's Note}

Springer Nature remains neutral with regard to jurisdictional claims in published maps and institutional affiliations.

\section{Author details}

${ }^{1}$ IRCCS Rizzoli Orthopedic Institute, Bologna, Italy. ${ }^{2}$ Laboratory of Preclinical and Surgical Studies, IRCCS Rizzoli Orthopedic Institute, Bologna, Italy. ${ }^{3}$ IGEA SpA, Clinical Biophysics, Carpi, Modena, Italy.

Received: 7 June 2018 Accepted: 7 August 2018

Published online: 20 August 2018

\section{References}

1. Carvalho AF, Hyphantis T, Sales PMG, Soeiro-de-Souza MG, Macêdo DS, Cha DS, et al. Major depressive disorder in breast cancer: a critical systematic review of pharmacological and psychotherapeutic clinical trials. Cancer Treat Rev. 2014:40:349-55.

2. Cancer Statistics Review, 1975-2013 - Previous Version - SEER Cancer Statistics Review [Internet]. [cited 25 Jul 2017]. Available from: https://seer. cancer.gov/archive/csr/1975_2013/

3. Eckhardt BL, Francis PA, Parker BS, Anderson RL. Strategies for the discovery and development of therapies for metastatic breast cancer. Nat Rev Drug Discov. 2012;11:479-97.

4. Kennecke H, Yerushalmi R, Woods R, Cheang MCU, Voduc D, Speers CH, et al. Metastatic behavior of breast cancer subtypes. J Clin Oncol Off J Am Soc Clin Oncol. 2010:28:3271-7.

5. Largillier R, Ferrero J-M, Doyen J, Barriere J, Namer M, Mari V, et al. Prognostic factors in 1,038 women with metastatic breast cancer. Ann Oncol Off J Eur Soc Med Oncol. 2008;19:2012-9.

6. Chang J, Clark GM, Allred DC, Mohsin S, Chamness G, Elledge RM. Survival of patients with metastatic breast carcinoma: importance of prognostic markers of the primary tumor. Cancer. 2003:97:545-53.

7. Weilbaecher KN, Guise TA, McCauley LK. Cancer to bone: a fatal attraction. Nat Rev Cancer. 2011:11:411-25.

8. Coleman RE. Metastatic bone disease: clinical features, pathophysiology and treatment strategies. Cancer Treat Rev. 2001;27:165-76.

9. Bendre MS, Montague DC, Peery T, Akel NS, Gaddy D, Suva LJ. Interleukin-8 stimulation of osteoclastogenesis and bone resorption is a mechanism for the increased osteolysis of metastatic bone disease. Bone. 2003:33:28-37.

10. Bendre MS, Margulies AG, Walser B, Akel NS, Bhattacharrya S, Skinner RA, et al. Tumor-derived interleukin-8 stimulates osteolysis independent of the receptor activator of nuclear factor-kappaB ligand pathway. Cancer Res. 2005:65:11001-9.

11. Ohshiba T, Miyaura C, Ito A. Role of prostaglandin E produced by osteoblasts in osteolysis due to bone metastasis. Biochem Biophys Res Commun. 2003;300:957-64.

12. Mundy GR. Mechanisms of bone metastasis. Cancer. 1997;80:1546-56.

13. Morgan $\mathrm{H}$, Tumber A, Hill PA. Breast cancer cells induce osteoclast formation by stimulating host IL-11 production and downregulating granulocyte/macrophage colony-stimulating factor. Int J Cancer. 2004;109: 653-60

14. Piccioli A, Maccauro G, Scaramuzzo L, Graci C, Spinelli MS. Surgical treatment of impending and pathological fractures of tibia. Injury. 2013;44:1092-6.

15. Piccioli A, Maccauro G, Rossi B, Scaramuzzo L, Frenos F, Capanna R. Surgical treatment of pathologic fractures of humerus. Injury. 2010;41:1112-6.
16. Palma E, Correia JDG, Campello MPC, Santos I. Bisphosphonates as radionuclide carriers for imaging or systemic therapy. Mol BioSyst. 2011;7: 2950-66.

17. Paes FM, Serafini AN. Systemic metabolic radiopharmaceutical therapy in the treatment of metastatic bone pain. Semin Nucl Med. 2010;40:89-104.

18. Bodei L, Lam M, Chiesa C, Flux G, Brans B, Chiti A, et al. EANM procedure guideline for treatment of refractory metastatic bone pain. Eur J Nucl Med Mol Imaging. 2008:35:1934-40.

19. Rosenthal DI. Radiofrequency treatment. Orthop Clin North Am. 2006;37: 475-84. viii

20. Simon CJ, Dupuy DE. Percutaneous minimally invasive therapies in the treatment of bone tumors: thermal ablation. Semin Musculoskelet Radiol. 2006:10:137-44

21. Capanna R, Campanacci DA. The treatment of metastases in the appendicular skeleton. J Bone Joint Surg Br. 2001:83:471-81.

22. Nakada K, Kasai K, Watanabe Y, Katoh C, Kanegae K, Tsukamoto E, et al. Treatment of radioiodine-negative bone metastasis from papillary thyroid carcinoma with percutaneous ethanol injection therapy. Ann Nucl Med. 1996;10:441-4.

23. Bianchi G, Campanacci L, Rimondi E, Ruggieri P. Palliative treatments: Electrochemotherapy and thermoablation. 2012; Available from: https:// moh-it.pure.elsevier.com/en/publications/palliative-treatmentselectrochemotherapy-and-thermoablation

24. Catane R, Beck A, Inbar Y, Rabin T, Shabshin N, Hengst S, et al. MR-guided focused ultrasound surgery (MRgFUS) for the palliation of pain in patients with bone metastases--preliminary clinical experience. Ann Oncol Off J Eur Soc Med Oncol. 2007;18:163-7.

25. Xin Z, Lin G, Lei H, Lue TF, Guo Y. Clinical applications of low-intensity pulsed ultrasound and its potential role in urology. Transl Androl Urol. 2016;5:255-66.

26. Chu KF, Dupuy DE. Thermal ablation of tumours: biological mechanisms and advances in therapy. Nat Rev Cancer. 2014;14:199-208.

27. ter Haar G. Therapeutic applications of ultrasound. Prog Biophys Mol Biol. 2007:93:111-29.

28. Nolte PA, van der Krans A, Patka P, Janssen IM, Ryaby JP, Albers GH. Lowintensity pulsed ultrasound in the treatment of nonunions. J Trauma. 2001; 51:693-702. discussion 702-703

29. Rutten S, Nolte PA, Guit GL, Bouman DE, Albers GHR. Use of low-intensity pulsed ultrasound for posttraumatic nonunions of the tibia: a review of patients treated in the Netherlands. J Trauma. 2007;62:902-8.

30. Foley JL, Vaezy S, Crum LA. Applications of high-intensity focused ultrasound in medicine: spotlight on neurological applications. Appl Acoust. 2007;68:245-59.

31. Mauck RL, Nicoll SB, Seyhan SL, Ateshian GA, Hung CT. Synergistic action of growth factors and dynamic loading for articular cartilage tissue engineering. Tissue Eng. 2003;9:597-611.

32. Schulte FA, Ruffoni D, Lambers FM, Christen D, Webster DJ, Kuhn G, et al. Local mechanical stimuli regulate bone formation and resorption in mice at the tissue level. PLoS One. 2013;8:e62172.

33. Costa V, Carina V, Fontana S, De Luca A, Monteleone F, Pagani S, et al. Osteogenic commitment and differentiation of human mesenchymal stem cells by low-intensity pulsed ultrasound stimulation. J Cell Physiol. 2018;233: 1558-73.

34. Erdogan O, Esen E. Biological aspects and clinical importance of ultrasound therapy in bone healing. J Ultrasound Med Off J Am Inst Ultrasound Med. 2009:28:765-76.

35. Fung $\mathrm{C}-\mathrm{H}$, Cheung W-H, Pounder NM, Harrison A, Leung K-S. Osteocytes exposed to far field of therapeutic ultrasound promotes osteogenic cellular activities in pre-osteoblasts through soluble factors. Ultrasonics. 2014;54: 1358-65.

36. Li X, Li J, Cheng K, Lin Q, Wang D, Zhang H, et al. Effect of low-intensity pulsed ultrasound on MMP-13 and MAPKs signaling pathway in rabbit knee osteoarthritis. Cell Biochem Biophys. 2011:61:427-34.

37. Sawai Y, Murata H, Koto K, Matsui T, Horie N, Ashihara E, et al. Effects of low-intensity pulsed ultrasound on osteosarcoma and cancer cells. Oncol Rep. 2012;28:481-6.

38. Guo Y, Tiedemann K, Khalil JA, Russo C, Siegel PM, Komarova SV. Osteoclast precursors acquire sensitivity to breast cancer derived factors early in differentiation. Bone. 2008:43:386-93.

39. Raimondi L, De Luca A, Amodio N, Manno M, Raccosta S, Taverna S, et al. Involvement of multiple myeloma cell-derived exosomes in osteoclast differentiation. Oncotarget. 2015;6:13772-89. 
40. Lin C-W, Shen S-C, Ko C-H, Lin H-Y, Chen Y-C. Reciprocal activation of macrophages and breast carcinoma cells by nitric oxide and colonystimulating factor-1. Carcinogenesis. 2010;31:2039-48.

41. Carina V, Costa V, Raimondi L, Pagani S, Sartori M, Figallo E, et al. Effect of low-intensity pulsed ultrasound on osteogenic human mesenchymal stem cells commitment in a new bone scaffold. J Appl Biomater Funct Mater. 2017; 15:e215-22.

42. Livak KJ, Schmittgen TD. Analysis of relative gene expression data using real-time quantitative PCR and the 2(-Delta Delta C (T)) method. Methods San Diego Calif. 2001;25:402-8.

43. R Foundation for Statistical Computing. R: a language and environment for statistical computing [Internet]. GBIF.ORG. 2015. Available from: http://www. gbif.org/resource/81287

44. WOOD AKW, SEHGAL CM. A review of low-intensity ultrasound for cancer therapy. Ultrasound Med Biol. 2015;41:905-28.

45. Zhang N, Chow SK-H, Leung K-S, Cheung W-H. Ultrasound as a stimulus for musculoskeletal disorders. J Orthop Transl. 2017:9:52-9.

46. Watson T. Ultrasound in contemporary physiotherapy practice. Ultrasonics. 2008:48:321-9.

47. Suh YK, Kang S. Acoustic Streaming. Encycl Microfluid Nanofluidics [Internet]. Springer, Boston, MA; 2014 [cited 17 May 2018]. p. 1-15. Available from: https://ink.springer.com/referenceworkentry/10.1007/978-3-642-27758-0_12-2

48. El-Mowafi $\mathrm{H}$, Mohsen M. The effect of low-intensity pulsed ultrasound on callus maturation in tibial distraction osteogenesis. Int Orthop. 2005;29:121-4.

49. Akiyama $\mathrm{H}$, Hachiya $\mathrm{Y}$, Otsuka $\mathrm{H}$, Kurisuno M, Kawanabe $\mathrm{K}$, Katayama $\mathrm{N}$, et al. Low-intensity pulsed ultrasound therapy stimulates callus formation between host femur and cortical onlay strut allograft. Ultrasound Med Biol. 2014;40:1197-203.

50. Bashardoust Tajali S, Houghton P, MacDermid JC, Grewal R. Effects of lowintensity pulsed ultrasound therapy on fracture healing: a systematic review and meta-analysis. Am J Phys Med Rehabil. 2012;91:349-67.

51. Unsworth J, Kaneez S, Harris S, Ridgway J, Fenwick S, Chenery D, et al. Pulsed low intensity ultrasound enhances mineralisation in preosteoblast cells. Ultrasound Med Biol. 2007;33:1468-74.

52. Busse JW, Bhandari M, Einhorn TA, Heckman JD, Leung K-S, Schemitsch E, et al. Trial to re-evaluate ultrasound in the treatment of tibial fractures (TRUST): a multicenter randomized pilot study. Trials. 2014;15:206.

53. Tempany CMC, McDannold NJ, Hynynen K, Jolesz FA. Focused ultrasound surgery in oncology: overview and principles. Radiology. 2011;259:39-56.

54. Napoli A, Anzidei M, Ciolina F, Marotta E, Cavallo Marincola B, Brachetti G, et al. MR-guided high-intensity focused ultrasound: current status of an emerging technology. Cardiovasc Intervent Radiol. 2013;36:1190-203.

55. Hurwitz MD, Ghanouni P, Kanaev SV, lozeffi D, Gianfelice D, Fennessy FM, et al. Magnetic resonance-guided focused ultrasound for patients with painful bone metastases: phase III trial results. J Natl Cancer Inst. 2014;106(5).

56. Malietzis G, Monzon L, Hand J, Wasan H, Leen E, Abel M, et al. Highintensity focused ultrasound: advances in technology and experimental trials support enhanced utility of focused ultrasound surgery in oncology. $\mathrm{Br}$ J Radiol. 2013;86:20130044.

57. Wu J, Nyborg WL. Ultrasound, cavitation bubbles and their interaction with cells. Adv Drug Deliv Rev. 2008;60:1103-16.

58. Yudina A, Moonen C. Ultrasound-induced cell permeabilisation and hyperthermia: strategies for local delivery of compounds with intracellular mode of action. Int J Hyperth Off J Eur Soc Hyperthermic Oncol North Am Hyperth Group. 2012;28:311-9.

59. Evjen TJ, Hagtvet E, Moussatov A, Røgnvaldsson S, Mestas J-L, Fowler RA, et al. In vivo monitoring of liposomal release in tumours following ultrasound stimulation. Eur J Pharm Biopharm Off J Arbeitsgemeinschaft Pharm Verfahrenstechnik EV. 2013;84:526-31.

60. Raimondi L, Amodio N, Di Martino MT, Altomare E, Leotta M, Caracciolo D, et al. Targeting of multiple myeloma-related angiogenesis by miR-199a-5p mimics: in vitro and in vivo anti-tumor activity. Oncotarget. 2014;5:3039-54.

61. Costa AG, Cusano NE, Silva BC, Cremers S, Bilezikian JP. Cathepsin K: its skeletal actions and role as a therapeutic target in osteoporosis. Nat Rev Rheumatol. 2011;7:447-56.

62. Aimes RT, Quigley JP. Matrix metalloproteinase-2 is an interstitial collagenase. Inhibitor-free enzyme catalyzes the cleavage of collagen fibrils and soluble native type I collagen generating the specific 3/4- and 1/4length fragments. J Biol Chem. 1995;270:5872-6.

63. Kusano K, Miyaura C, Inada M, Tamura T, Ito A, Nagase $H$, et al. Regulation of matrix metalloproteinases (MMP-2, $-3,-9$, and -13 ) by interleukin-1 and interleukin-6 in mouse calvaria: association of MMP induction with bone resorption. Endocrinology. 1998;139:1338-45.

64. Feres MFN, Kucharski C, Diar-Bakirly S, El-Bialy T. Effect of low-intensity pulsed ultrasound on the activity of osteoclasts: an in vitro study. Arch Oral Biol. 2016;70:73-8.

65. Miyazaki T, Miyauchi S, Anada T, Imaizumi H, Suzuki O. Evaluation of osteoclastic resorption activity using calcium phosphate coating combined with labeled polyanion. Anal Biochem. 2011;410:7-12.

66. Monici M, Bernabei PA, Basile V, Romano G, Conti A, Breschi L, et al. Can ultrasound counteract bone loss? Effect of low-intensity ultrasound stimulation on a model of osteoclastic precursor. Acta Astronaut. 2007;60: 383-90.

67. Chen SH, Wu CC, Wang SH, Li WT. The inhibition effect of low-intensity pulsed ultrasound on osteoclasts progenitor cells. 2012 IEEE Int Ultrason Symp. 2012:607-10. https://doi.org/10.1109/ULTSYM.2012.0151.

68. De Luca A, Raimondi L, Salamanna F, Carina V, Costa V, Bellavia D, et al. Relevance of $3 d$ culture systems to study osteosarcoma environment. J Exp Clin Cancer Res CR. 2018;37:2.

69. Fini M, Salamanna F, Parrilli A, Martini L, Cadossi M, Maglio M, et al. Electrochemotherapy is effective in the treatment of rat bone metastases. Clin Exp Metastasis. 2013;30:1033-45.

\section{Ready to submit your research? Choose BMC and benefit from:}

- fast, convenient online submission

- thorough peer review by experienced researchers in your field

- rapid publication on acceptance

- support for research data, including large and complex data types

- gold Open Access which fosters wider collaboration and increased citations

- maximum visibility for your research: over $100 \mathrm{M}$ website views per year

At BMC, research is always in progress.

Learn more biomedcentral.com/submissions 